\title{
Ablasjonsbehandling av takyarytmier hos barn og unge
}

\begin{abstract}
Sammendrag
Bakgrunn. I de senere år har man fått $ø$ kt erfaring med ablasjonsbehandling av barn og unge med hjerterytmeforstyrrelser. Hensikten med denne artikkelen er å belyse resultatene etter ablasjonsbehandling av takykardier hos individer under 18 år ved Haukeland universitetssykehus.
\end{abstract}

Materiale og metode. Fra 1992 til 2007 gjennomgikk 141 pasienter i aldersgruppen 5-17 år med dokumentert hjertearytmi elektrofysiologisk undersøkelse med etterfølgende ablasjonsbehandling.

Resultater. Ablasjonsbehandlingen var vellykket hos 138 (98\%) av de 141 pasientene. 16 av disse 138 måtte rebehandles opptil to ganger (tre pasienter) før arytmisubstratet bortfalt. 81 pasienter $(57 \%)$ hadde aksessoriske ledningsbaner, hvorav 33 hadde klassisk Wolff-Parkinson-Whites syndrom og 48 atrioventrikulær «reentry»-takykardi med skjult aksessorisk bane. 52 (37\%) hadde atrioventrikulær nodal «reentry»-takykardi. Åtte pasienter $(6 \%)$ hadde andre atriale eller ventrikulære takyarytmier, og fire (3\%) hadde organisk hjertefeil. Anvendelse av tredimensjonalt registreringssystem var avgjørende for vellykket behandling av pasienter med kompliserte hjertelidelser. Prosedyrerelaterte komplikasjoner forekom hos 2/141 pasienter $(1,4 \%)$ - én fikk forbigående tredjegrads og den andre vedvarende første grads atrioventrikulært blokk, uten at dette medførte spesielle terapeutiske tiltak.

Fortolkning. Kateterablasjon av takykardi hos barn og unge er en trygg behandlingsmetode med høy suksessrate og få komplikasjoner og bør foretrekkes fremfor symptomatisk medikamentell behandling.
Ole-Jørgen Ohm

Institutt for indremedisin

Universitetet i Bergen

Per Ivar Hoff

Hjerteavdelingen

Haukeland universitetssykehus

Lars Mikal Aasen

Eivind Solheim

Institutt for indremedisin

Universitetet i Bergen

\section{Peter Schuster}

Morten Kristian Off

Jian Chen

jian.chen@med.uib.no

Hjerteavdelingen

Haukeland universitetssykehus

5021 Bergen

Radiofrekvensablasjon av pasienter med takykardier ble klinisk tilgjengelig fra 1987 (1). Ved Haukeland universitetssykehus ble dette et behandlingstilbud fra 1991, og det har stadig økt i omfang. Hittil er mer enn 3000 personer i alle aldersgrupper blitt behandlet. Den teknologiske utviklingen har gjort det mulig å tilby radiofrekvensablasjon til stadig nye pasientgrupper. Det har vært usikkerhet om hvorvidt barn og unge bør få slik behandling, blant annet på grunn av faren for komplikasjoner (2, 3). Hensikten med denne studien er å belyse våre behandlingsresultater for denne gruppen.

\section{Metoder \\ Pasienter}

Dette er en retrospektiv undersøkelse av alle pasienter under 18 år som ble henvist og behandlet med radiofrekvensablasjon og/eller ablasjon med fryseteknikk (kryoablasjon) i årene 1992-2007 i henhold til operasjonsprotokoll. Alle prosedyrer blir fortløpende registrert i protokollen, og disse data er grunnlaget for denne artikkelen.

Innsamlede data omfattet alder, kjønn, indikasjon for ablasjon, arytmi og lokalisasjon av arytmisubstrat. Indikasjon var symptomgivende takykardi, sviktende medikamentell behandling, livstruende arytmi eller hjertesvikt. Arytmiene ble klassifisert som Wolff-Parkinson-Whites syndrom (WPW-syndrom), skjult ekstra ledningsbane med atrioventrikulær «reentry»-takykardi (AVRT) inkludert PJRT (permanent junctional reciprocating tachycardia - norsk betegnelse mangler), atrioventrikulær nodal «reentry»-takykardi (AVNRT), atriale takyarytmier bestående av fokal atrietakykardi, atrieflutter og atrieflimmer samt ventrikkeltakykardier (tab 1).

\section{Prosedyre}

Hos barn under 15 år foregikk undersøkelsen i generell anestesi, hos de øvrige i lokalanestesi og sedasjon.

Elektrofysiologisk undersøkelse ble foretatt etter konvensjonelle metoder med innføring av katetre via blodårer i lyskene for kartlegging av arytmisubstrat og deretter anvendelse av en radiobølgegenerator (Stockert, Biosense Webster). Fem pasienter ble behandlet med kryoablasjon (Cryocath). Plassering av katetrene foregikk under røntgengjennomlysning. Fra 2002 ble et nytt elektroanatomisk kartleggingssystem (CARTO, Biosense Webster) tilgjengelig, og fra 2007 et magnetisk navigasjonssystem (Niobe, Stereotaxis), som ble benyttet hos pasienter med spesielt kompliserte arytmier.

Vellykket prosedyre ble definert som bortfall av arytmisubstrat og at ingen arytmi lot seg utløse med elektrofysiologisk undersøkelse ved avslutning av prosedyren.

\section{Oppfølging}

Etter gjennomført behandling ble pasientene observert ett døgn i avdelingen under telemetriovervåking. Den videre oppfølging foregikk enten fra henvisende sykehus/lege (oftest pediater) eller ved sykehusets poliklinikk, med regelmessig kontroll i inntil 12 måneder. Senere ble de som hadde symptomer kontrollert ved behov. Alle med klinisk dokumentert residiv av takyarytmi ble mottatt til ny elektrofysiologisk undersøkelse og eventuell ablasjonsbehandling.

\section{Resultater}

Totalt 71 jenter og 70 gutter ble behandlet. Antall pasienter samt yngste pasient behandlet det enkelte år er vist i figur 1 og tabell 1. Pasientene var i alderen 5-17 år (13,3 år $\pm 3,5$ år). 29 pasienter $(20,6 \%)$ var ti år eller yngre. Det overveiende antall pasienter - 114/141 $(81 \%)$ - tilhørte egen helseregion, seks var henvist fra Helse Sør-Øst, 18 fra Helse MidtNorge og tre fra Helse Nord. Varigheten av anfallssymptomer fremgår av figur 2 .

\section{Hovedbudskap}

- Takyarytmier kan kureres med ablasjon

- Metoden har høy suksessrate og innebærer få komplikasjoner

- Behandlingen bør være førstevalget hos barn og unge med gjentatte anfall 


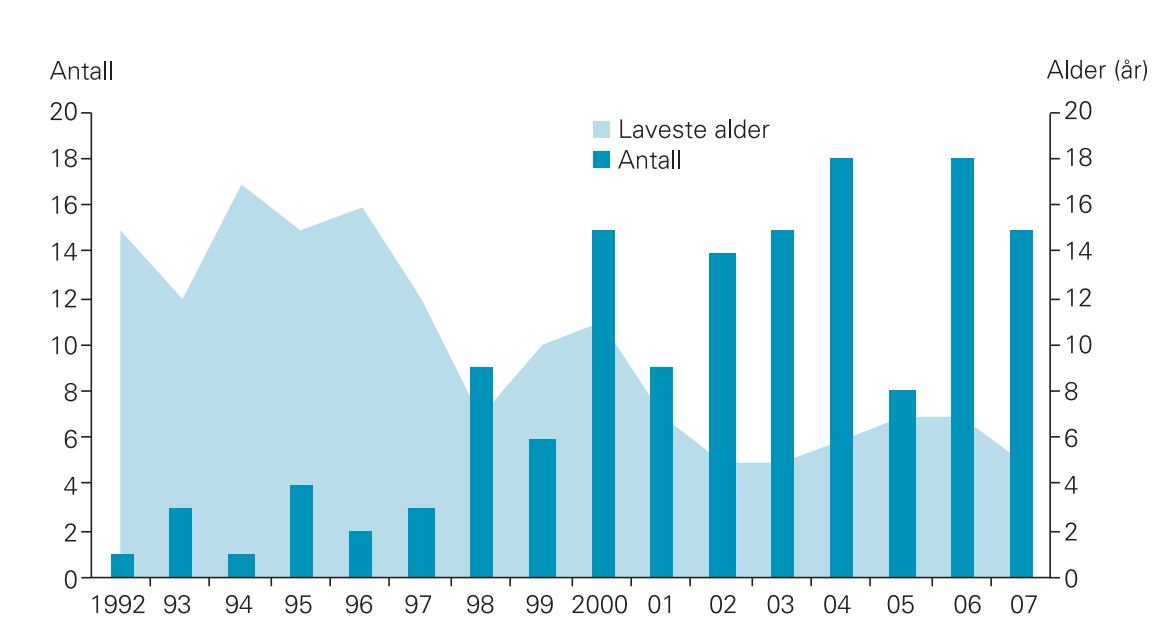

Figur 1 Antall pasienter behandlet per år og alder for yngste pasient behandlet i hvert av årene

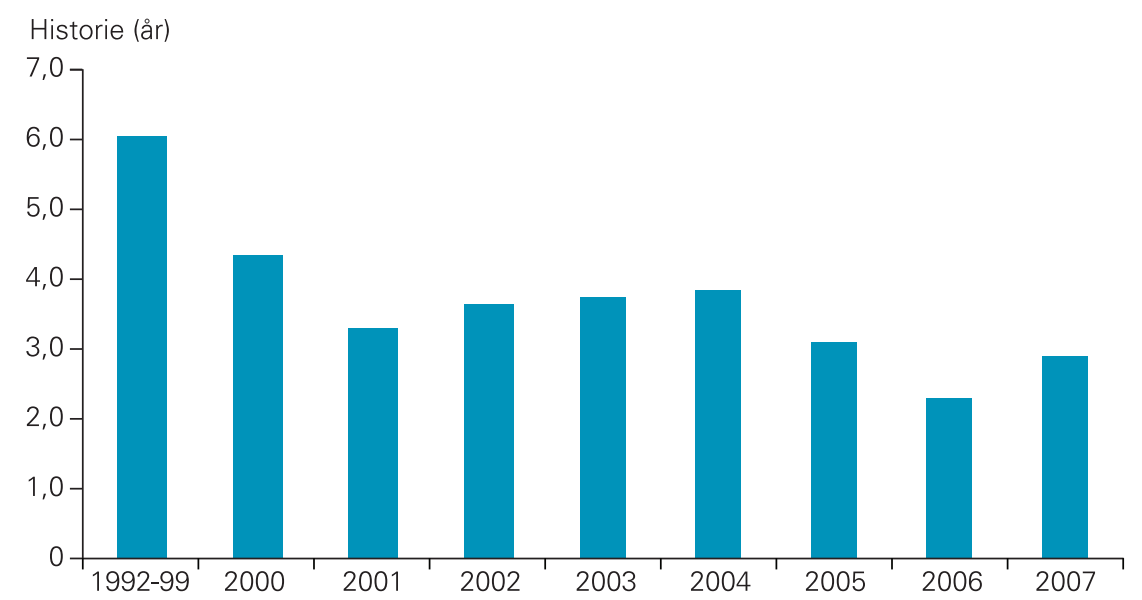

Figur 2 Gjennomsnittlig tid fra symptomdebut til ablasjonsbehandling de enkelte år
Tabell 1 viser detaljer om pasientene. 133/141 (94\%) hadde banebetingede takykardier, hvorav $81(57 \%)$ atrioventrikulær «reentry»-takykardi og 52 (37\%) atrioventrikulær nodal «reentry»-takykardi. Lokaliseringen av ledningsbanene som forårsaket atrioventrikulær «reentry»-takykardi fordelte seg på 51 venstresidige og 30 høyresidige baner (fig 3). Vellykket behandling ble oppnådd hos 138/141 (98\%) av pasientene. Ett eksempel er vist i figur 4. Kryoablasjon var vellykket hos tre pasienter, men hos to måtte man supplere med radiofrekvensablasjon før arytmisubstratet forsvant.

Hos 17/141 pasienter (12\%) oppsto det enten residiv eller første behandling var mislykket. Vanligst var det ved atrioventrikulær «reentry»-takykardi - hos 12/81 (14,8\%) mens det hos dem med atrioventrikulær nodal «reentry»-takykardi forekom hos $3 / 52$ $(5,8 \%)$.

Prosedyren måtte gjentas én gang hos 13 pasienter og to ganger hos tre pasienter pga. residiv av arytmi. Hos én pasient med fokal atrietakykardi ble det utført tre nye prosedyrer - uten at man fikk fjernet arytmisubstratet.

Hos én pasient med Wolff-ParkinsonWhites syndrom residiverte deltabølgen i EKG. Ved oppfølging over tre år var han så lite symptomatisk at han ikke ønsket ny behandling. Én pasient med atrieflimmer fikk residiv etter lungeveneisolasjon, men man har ikke funnet indikasjon for nytt behandlingsforsøk.

\section{Pasienter med organisk hjertefeil}

Tabell 2 viser detaljer om de fire pasientene som hadde organisk hjertefeil. Hos to forelå det kardiomyopati. En av dem, som hadde vært behandlet med cytostatika etter operasjon for Wilms tumor, falt plutselig om med hjertestans utenfor sykehus. Elektrofysiologisk undersøkelse viste at det forelå en klas-

Tabell 1 Pasientkarakteristika og resultat av ablasjonsbehandlingen. WPW-syndrom = Wolff-Parkinson-Whites syndrom, AVRT = atrioventrikulær «reentry»-takykardi, AVNRT = atrioventrikulær nodal «reentry»-takykardi, PJRT = permanent junctional reciprocating tachycardia, RVOT = høyre ventrikkels utløps-takykardi

\begin{tabular}{|c|c|c|c|c|c|c|c|c|c|c|c|}
\hline \multirow[b]{2}{*}{ Diagnose } & \multirow[b]{2}{*}{ Antall } & \multirow{2}{*}{$\begin{array}{c}\text { Alder (år) } \\
\text { (middel } \pm \text { SD) }\end{array}$} & \multicolumn{2}{|c|}{ Kjønn } & \multirow{2}{*}{$\begin{array}{c}\text { Organisk hjerte- } \\
\text { sykdom }\end{array}$} & \multicolumn{2}{|c|}{ Antall prosedyrer } & \multicolumn{2}{|c|}{$\begin{array}{l}\text { Vellykkede } \\
\text { prosedyrer }\end{array}$} & \multicolumn{2}{|c|}{ Sluttresultat } \\
\hline & & & o & q & & Gjentatte & Totalt & Antall & $(\%)$ & Pasienter & (\%) \\
\hline WPW-syndrom & 33 & $\begin{array}{c}6-17 \\
12,6 \pm 4,0)\end{array}$ & 19 & 14 & 0 & 5 & 38 & 37 & (97) & 32 & (97) \\
\hline $\begin{array}{l}\text { Skjult AVRT } \\
\text { Typisk } \\
\text { PJRT }\end{array}$ & $\begin{array}{r}48 \\
47 \\
1\end{array}$ & $\begin{array}{c}5-17 \\
(13,0 \pm 3,4)\end{array}$ & 26 & 22 & 1 & 7 & 55 & 55 & $(100)$ & 48 & (100) \\
\hline AVNRT & 52 & $\begin{array}{c}7-17 \\
(13,6 \pm 3,3)\end{array}$ & 22 & 30 & 1 & 3 & 55 & 55 & $(100)$ & 52 & (100) \\
\hline $\begin{array}{l}\text { Atriale takyarytmier } \\
\text { Atrietakykardi } \\
\text { Atrieflutter } \\
\text { Atrieflimmer }\end{array}$ & $\begin{array}{l}5 \\
3 \\
1 \\
1\end{array}$ & $\begin{array}{c}14-16 \\
(15,2 \pm 0,8)\end{array}$ & 2 & 3 & 2 & 4 & 9 & 4 & (44) & 3 & (60) \\
\hline $\begin{array}{l}\text { Ventrikkeltakykardi } \\
\text { Venstre ventrikkel } \\
\text { RVOT }\end{array}$ & $\begin{array}{l}3 \\
2 \\
1\end{array}$ & $\begin{array}{c}14-16 \\
(15,0 \pm 1,0)\end{array}$ & 1 & 2 & 0 & 3 & 6 & 6 & $(100)$ & 3 & (100) \\
\hline Totalt & 141 & $\begin{array}{c}5-17 \\
(13,3 \pm 3,5)\end{array}$ & 70 & 71 & 4 & 22 & 163 & 157 & (96) & 138 & (98) \\
\hline
\end{tabular}


sisk atrioventrikulær nodal «reentry»-takykardi, men ikke utløsbar ventrikulær takyarytmi. Man antok derfor at pasientens hjertestans skyldtes den supraventrikulære takykardien, som ble behandlet med ablasjon. Hun fikk imidlertid ny hjertestans og det ble implantert kardioverterdefibrillator. Enheten ble aktivert for behandling av takyarytmi tre år senere, men måtte skiftes pga. teknisk svikt ett år etter det.

En 16 år gammel gutt var fem år gammel blitt Fontan-operert. Han fikk arrbetinget atrieflutter og ble vellykket behandlet med ablasjon (fig 5). Etter siste informasjon til oss fikk han økende høyre atriedilatasjon og nye forkammerarytmier. Som 20-åring gjennomgikk han derfor et nytt korrigerende kirurgisk inngrep for sin grunnlidelse.

En 14 år gammel gutt ble hjertetransplantert vel to år gammel for kongestiv kardiomyopati. På grunn av uopphørlig takykardi som hadde vedvart i 14 måneder - først tolket som sinustakykardi - og utvikling av hjertesvikt ble han henvist til elektrofysiologisk undersøkelse. Ved anvendelse av elektroanatomisk kartlegging av hjerteaktiviteten kunne man påvise at det forelå en fokal atrietakykardi med bidireksjonal atrioatrial ledning mellom donorhjertet og resipienthjertet (fig 6). Arytmien ble vellykket behandlet med ablasjon, og pasientens hjertesvikt gikk i regress.

En 15 år gammel pike som var operert for aortikoventrikulær tunnel, fikk vellykket behandling for skjult ledningsbane med atrioventrikulær «reentry»-takykardi.

\section{Komplikasjoner}

To pasienter med atrioventrikulær nodal «reentry»-takykardi fikk AV-blokk i forbindelse med prosedyren. Den ene fikk forbigående tredjegrads AV-blokk som ikke krevde videre behandling, hos den andre oppsto førstegrads AV-blokk som heller ikke medførte spesielle terapeutiske tiltak.

\section{Diskusjon}

Undersøkelsen viser at ablasjonsbehandling av barn og unge kan utføres med høy suksessrate og få komplikasjoner. Dette er i samsvar med resultatene fra andre publiserte studier (4-6). En forutsetning for vellykket behandling er nøyaktig kartlegging av de elektriske ledningsbanene med invasive elektrofysiologiske metoder. Som vist i figur 3 er de atrioventrikulære banene tilfeldig spredt rundt mitral- og trikuspidalklaffene. Tilbakefall av arytmi lot seg vellykket behandle hos alle unntatt én. Hos to pasienter ble det ikke funnet indikasjon for nytt behandlingsforsøk. De eneste komplikasjoner som oppsto, var AV-ledningsforstyrrelse hos to pasienter med ledningsbane nær det atrioventrikulære ledningssystem. Hos pasienter hvor risikoen for å fremkalle AV-blokk var stor, benyttet man kryoablasjon, en teknikk som gir muligheten til å teste virkningen på AV-ledningssystemet uten å skade dette per-

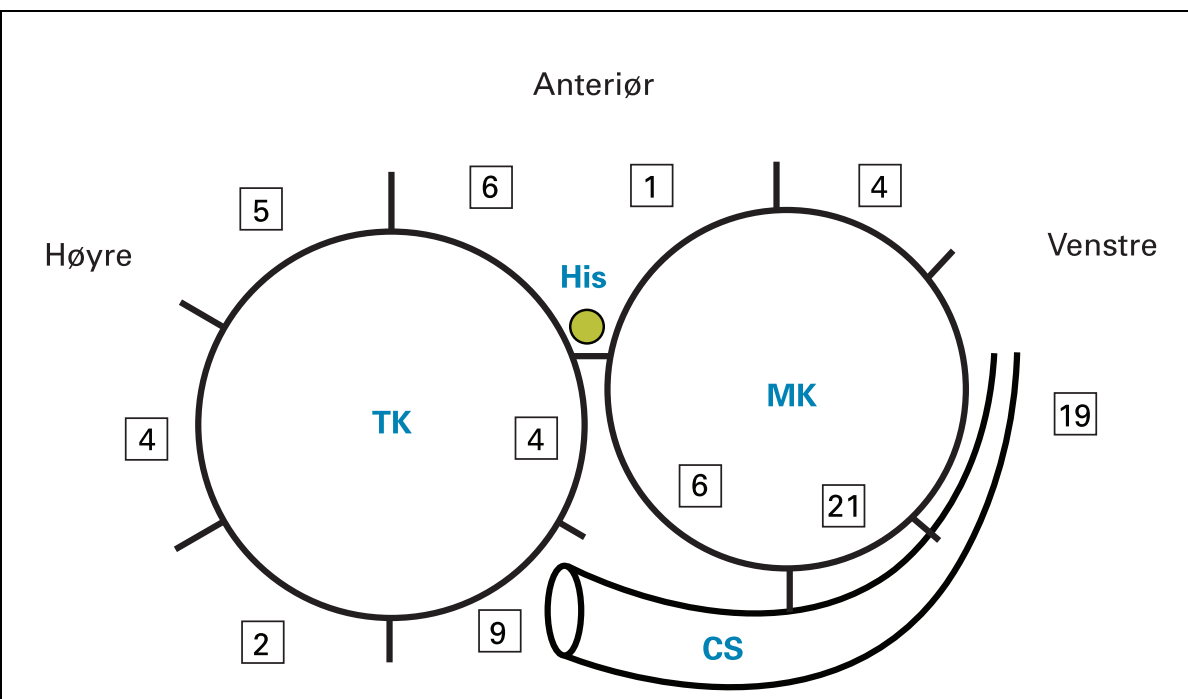

Posteriør

Figur 3 Lokalisering og antall atrioventrikulære ledningsbaner i relasjon til mitral- og trikuspidalklaffer (MK og TK), sinus coronarius (CS) og His-bunten sett nedenfra manent. Denne metoden må iblant suppleres med radiofrekvensablasjon.

Det har vært en viss tilbakeholdenhet med å anbefale ablasjon hos småbarn pga. frykt for skade på klaffer og koronarkar og økt arrdanning $i$ et voksende hjerte $(2,3,7)$. Det ble derfor foreslått en nedre aldersgrense på ti år for ablasjonsbehandling, også fordi et arytmisubstrat som har gitt alvorlige sym- ptomer i spedbarnsalderen, kan forandre seg $(8,9)$. Data angir at ablasjon kan utføres når barnet veier mer enn $15 \mathrm{~kg}$ (3). Kortere prosedyrer og moderne gjennomlysningsutstyr reduserer strålebelastningen til et minimum. Mange av barna kan ha betydelige symptomer som innvirker på livskvaliteten - de må avstå fra fysiske aktiviteter som ballspill og skigåing, som lett utløser anfall (10). Pasien-

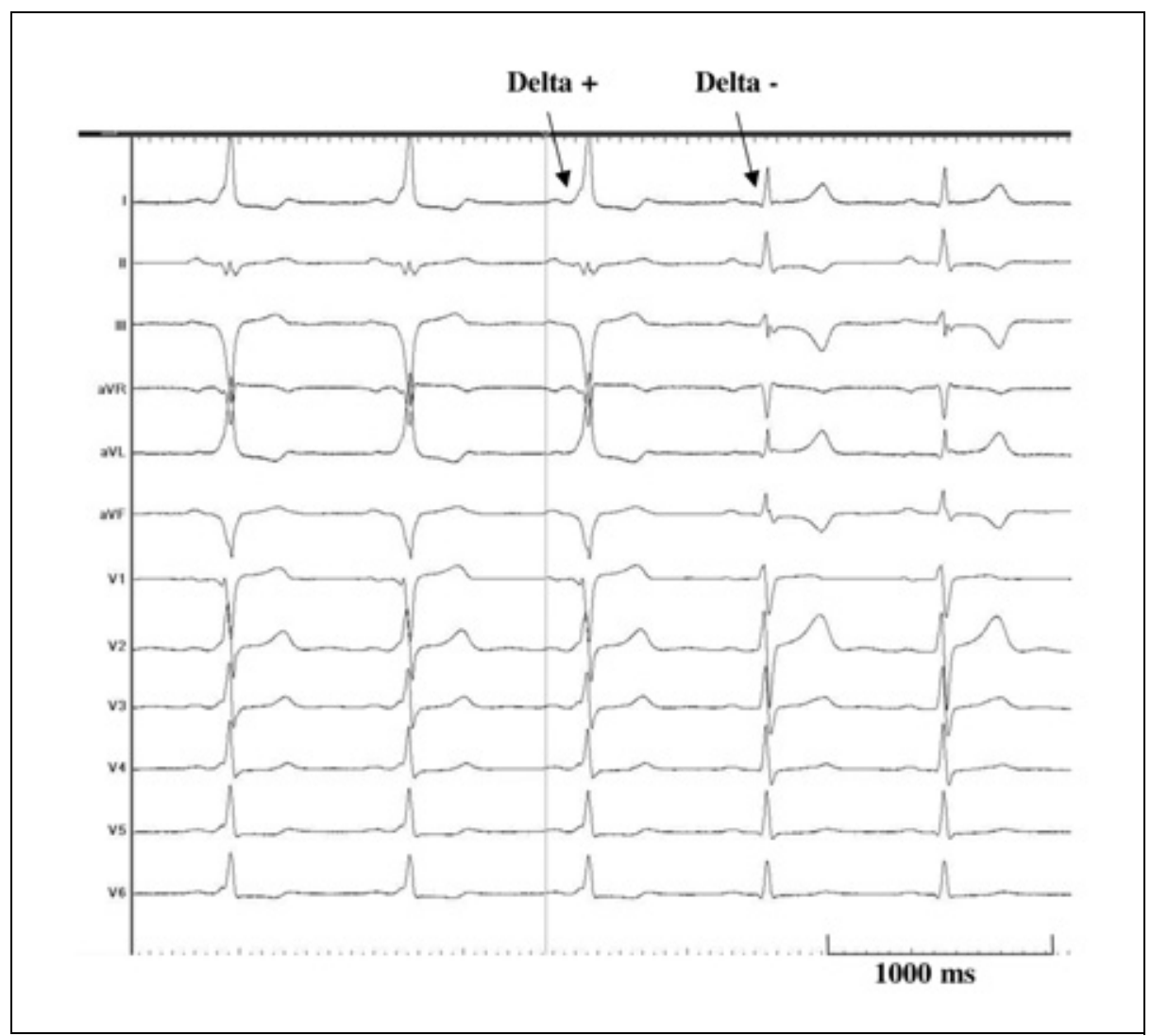

Figur 4 Klassisk Wolff-Parkinson-Whites syndrom. Preeksitasjon (deltabølge) som forsvinner under ablasjon samtidig som QRS-komplekser og T-takker skifter akse i standardavledningene og V1 


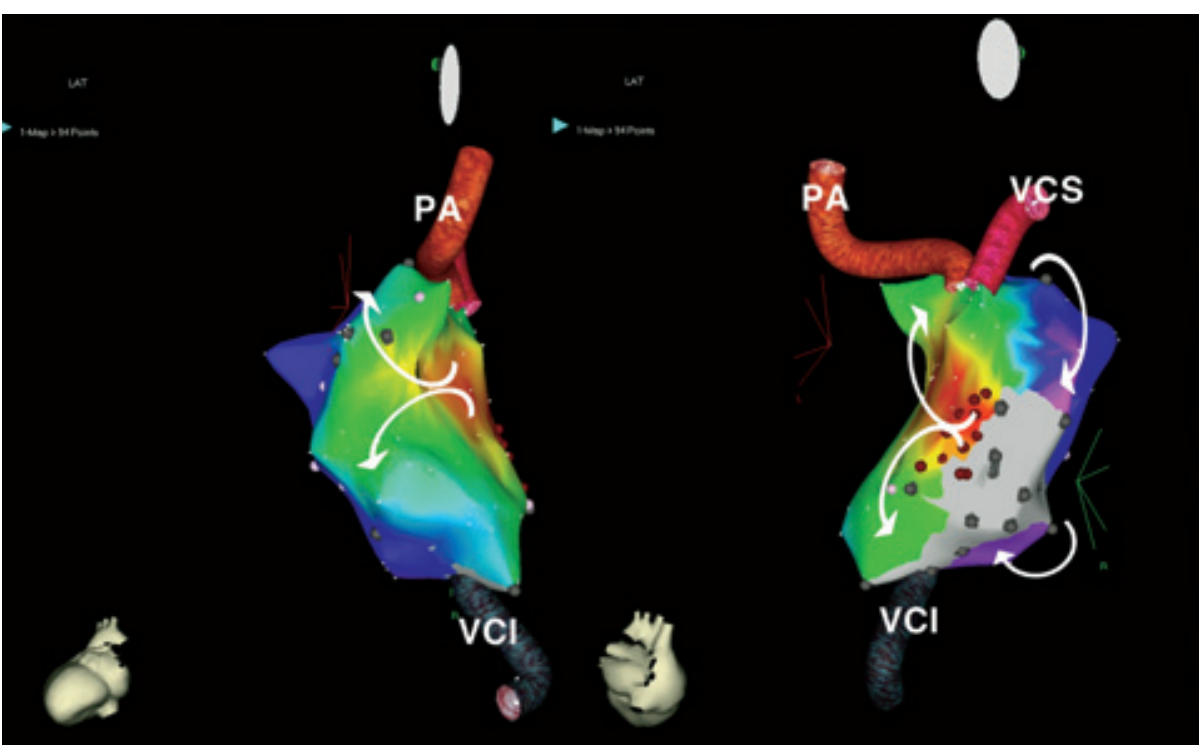

Figur 5 Elektroanatomisk bilde under atrieflutter fra Fontan-korrigert hjerte i venstre bakre skråprojeksjon (til venstre) og høyre bakre skråprojeksjon (til høyre). Hvite piler angir aktiveringssekvens i høyre atrium gjennom operasjonsarret (grått område). Røde punkter viser ablasjonslesjonene. PA: pulmonalarterie. VCI og VCS: v. cava inferior og v. cava superior

tens oppfatning (for de mindre barna foreldrenes) av plagene $\mathrm{i}$ form av symptomer og varighet er avgjørende for om man vil anbefale ablasjonsbehandling. Enkeltstående anfall er vanligvis ikke nok.

Forskjellige vagale manøvre kan benyttes i enkeltsituasjoner, men er ikke å anbefale ved stadig tilbakevendende anfall og kan føre til alvorlige komplikasjoner (11).

Det finnes i dag gode medikamenter til behandling av anfall (adenosin og flekainid) og til langtidsbehandling (flekainid) av arytmier som skyldes ekstra ledningsbaner (12). Ved sporadiske anfall er dette å foretrekke. For barn som har hyppige anfall og trenger fast medikasjon, er dette en dårlig løsning. Medikamentell langtidsbehandling, kanskje over flere tiår, er vanskelig å styre og kan ha betydelige bivirkninger. Det angis en tilbakefallsprosent på 30-50 ved medikamentell behandling (10). Kurativ behandling er derfor å foretrekke. Det økende antall henviste, samtidig som stadig yngre pasienter er be- handlet de siste årene (fig 1), er en konsekvens av at behandlingen er bedre kjent blant foreldre, pediatere og kardiologer. Dette har også ført til at varigheten av anfallssymptomer for kurativ behandling er gått ned - den ligger nå på mellom to og tre år (fig 2). Selv om pasientgruppen er liten, inngår den i den totale arytmivirksomhet av voksne pasienter som behandles med de samme metoder. Dermed kan man bygge på et betydelig erfaringsmateriale. Både atrioventrikulær 《reentry»-takykardi og atrioventrikulær nodal «reentry»-takykardi er nå en klasse I-indikasjon for ablasjon, ifølge internasjonale retningslinjer (10). I en prospektiv undersøkelse ble det ikke funnet forskjell mellom barn og voksne når det gjaldt suksess og komplikasjoner (5).

Behovet for ablasjonsbehandling av takyarytmier hos pasienter med medfødte hjertefeil før og etter kirurgisk korreksjon er ukjent. Et samlemateriale over en tiårsperiode fra et større utenlandsk referansesenter

Tabell 2 Arytmier hos pasienter med organisk hjertefeil. AVNRT = atrioventrikulær nodal «reentry»-takykardi, AVRT = atrioventrikulær «reentry»-takykardi

\begin{tabular}{|c|c|c|c|}
\hline Alder (år) & Kjønn & Sykdom & Arytmi \\
\hline 17 & ㅇ & $\begin{array}{l}\text { Kardiomyopati etter cytostatikabe- } \\
\text { handling pga. Wilms tumor }\end{array}$ & $\begin{array}{l}\text { AVNRT } \\
\text { Ventrikkelflimmer }\end{array}$ \\
\hline 16 & ô & $\begin{array}{l}\text { Singel ventrikkel, trikuspidalatresi, } \\
\text { ventrikkelseptumdefekt } \\
\text { Fontan-korrigert loperert } 5 \text { år } \\
\text { gammel) }\end{array}$ & Arrbetinget atrieflutter (fig 5) \\
\hline 14 & $\hat{\sigma}$ & $\begin{array}{l}\text { Kardiomyopati } \\
\text { Hjertetransplantert } \\
\text { (vel } 2 \text { år gammel) }\end{array}$ & Atrietakykardi (fig 6) \\
\hline 15 & q & $\begin{array}{l}\text { Aortikoventrikulær tunnel } \\
\text { (operert } 3 \text { md. gammel) }\end{array}$ & Skjult ekstra ledningsbane \\
\hline
\end{tabular}

thasienter, hvorav 56 barn under 16 år (13). Tre av 141 pasienter i vårt materiale hadde gjennomgått omfattende hjertekirurgiske inngrep (tab 2). Fokale og arrbetingede arytmier er ofte kompliserte å behandle. Med nytt avansert tredimensjonalt elektroanatomisk kartleggingsutstyr som letter forståelsen av arytmimekanismen var også behandlingen hos disse vellykket (tab 2, fig 5, fig 6).

Kurativ behandling av ventrikkeltakykardier er ofte en stor utfordring og forutsetter at pasienten tolererer takykardi under prosedyren. I en studie med 62 barn og unge med ventrikkeltakykardi og medfødt hjertefeil var det en rate for langtids behandlingsuksess på $61 \%$ (14).

Etter at man fikk tilgang til nytt magnetisk navigasjonsutstyr er det mulig å foreta ablasjon av pasienter med mer komplekse rytmeforstyrrelser og strukturelle forandringer $\mathrm{i}$ det kardiovaskulære system. Én av pasientene med venstre ventrikkel-takykardi har hatt to tilbakefall, men synes nå vellykket behandlet etter at siste ablasjonsprosedyre foregikk ved hjelp av magnetisk kateternavigasjon. Symptomatisk behandling med implanterbar kardioverterdefibrillator, som ville vært et alternativ, er ofte lite tilfredsstillende hos unge individer fordi enheten ikke sjelden aktiveres av sinustakykardi under fysisk belastning.

\section{Begrensninger}

Studien er retrospektiv. Det er ikke vanlig å gjennomføre systematiske kontroller av pasienter som har gjennomgått ablasjonsbehandling av takyarytmi utover 12 måneder. Residiv etter seks måneder er ifølge internasjonal litteratur sjeldent (4). Langtidsoppfølging er basert på tilbakemeldinger, epikriser og gjennomgang av journaler. 


\section{Konklusjon}

Ablasjonsbehandling av symptomgivende takyarytmier bør være førstevalget ved gjentatte anfall. Det er samme grad av suksess hos barn som hos voksne. Sikrere kunnskap om behandlingsmetoden har ført til at man har gitt tilbud til stadig yngre pasienter.

Studien har fått støtte fra Helse og rehabilitering.

Oppgitte interessekonflikter: Peter Schuster har fått støtte fra Nordisk Invasiv Elektrofysiologi Grant, Biosense Webster. De andre forfatterne har ingen oppgitte interessekonflikter.

\section{Litteratur}

1. Borggrefe M, Budde T, Podczeck A et al. High frequency alternating current ablation of an accessory pathway in humans. J Am Coll Cardiol 1987; 10: 576-82.

2. Kugler JD, Danford DA, Houston K et al. Radiofrequency catheter ablation for paroxysmal supraventricular tachycardia in children and adolescents without structural heart disease. Am J Cardiol 1997; 80: 1438-43.
3. Kugler JD, Danford DA, Deal BJ et al. Radiofrequency catheter ablation for tachyarrhythmias in children and adolescents. N Engl J Med 1994; 330 $1481-7$

4. Nielsen JC, Kottkamp H, Piorkowski C et al. Radiofrequency ablation in children and adolescents: results in 154 consecutive patients. Europace 2006; 8: 323-9.

5. Calkins $\mathrm{H}$, Yong $\mathrm{P}$. Miller JM et al. Catheter ablation of accessory pathways, atrioventricular nodal reentrant tachycardia, and the atrioventricular junction: final results of a prospective multicenter clinical trial. Circulation 1999; 99: 262-70.

6. Van Hare GF, Javitz H. Carmelli D et al. Prospective assessment after pediatric ablation: demographics, medical profiles, and initial outcomes. J Cardiovasc Electrophysiol 2004; 15: 759-70.

7. Saul JP. Hulse JE, Papagiannis J et al. Late enlargement of radiofrequency lesions in infant lambs; implications for ablation procedures in small children. Circulation 1994; 90: 492-9.

8. Case CL, Gillette PC, Oslizlok PC et al. Radiofrequency catheter ablation of incessant, medically resistant supraventricular tachycardias in infants and small children. J Am Coll Cardiol 1992; 20 : $1435-50$.

9. Dubin AM, Van Hare GF. Radiofrequency catheter ablation: indications and complications. Pediatr Cardiol 2000; 21: 551-6

10. Blomstrøm-Lundqvist C, Scheinman MM, Aliot EM et al. ACC/AHA/ESC guidelines for the manage- ment of patients with supraventricular arrhythmias - executive summary: a report of the American College of Cardiology/American Heart Association Task Society of Cardiology Committee for Practice Guidelines (Writing Committee to Develop Guidelines for the Management of Patients With Supraventricular Arrhythmias). J Am Coll Cardiol 2003; 42: 1493-531

11. Hoff PI, Færestrand S, Ohm O-J. Ocular deformation after long-term repeated bulbar compression for termination of paroxysmal tachycardia. Am J Cardiol 1992; 69: 1109-10.

12. Hoff PI, Tronstad A, Øie B et al. Electrophysiologic and clinical effects of flecainide for recurrent paroxysmal supraventricular tachycardia. Am J Cardiol 1988; 62: 585-9.

13. Hebe J, Hansen P, Ouyang F et al. Radiofrequency catheter ablation of tachycardia in patients with congenital heart disease. Pediatr Cardiol 2000; 21 557-75.

14. Morwood JG, Triedman JK, Berul Cl et al. Radiofrequency catheter ablation of ventricular tachycardia in children and young adults with congenital heart disease. Heart Rhythm 2004; 1: 301-8.

Manuskriptet ble mottatt 9.4. 2008 og godkjent 19.11. 2008. Medisinsk redaktør Åslaug Helland. 